\title{
5. Ten Days of Twitter
}

\#Intermediate \#Twitter \#ARU10DoT \#RUL10DoT
\#UCD10DoT \#LivUni10DoT \#YSJ10DoT \#10DOTTEL
\#HSLU10DoT \#MMJC10DoT

Mark Warnes

\section{Introduction}

Much has been written about digital literacy since Prensky's (2001) (now debunked) Digital Natives, Digital Immigrants, and the importance of digital literacy in higher education was highlighted by the inclusion of Dimension K4 of the UK Professional Standards Framework which describes 'The use and value of appropriate learning technologies' as Core Knowledge (HEA, 2011).

In recent years, the concept of digital literacy has expanded to include the use of social media in higher education, and national events such as the Social Media for Learning in Higher Education Conference (\#SocMedHE17) (Williams and Warnes, 2017) which has run at Sheffield Hallam since 2014, illustrate the importance of this development. Indeed, Jisc published their list of 'social media superstars' (Parr, 2017), including academics enhancing their teaching by incorporating social media such as Facebook, Instagram, YouTube, Snapchat, and, most frequently, Twitter.

It was to address staff development needs for the latter that Webster (@scholastic_rat) (2015) created 10 Days of Twitter (10DoT). The primary purpose of this is to gently introduce university staff to 
the use of Twitter in bitesize chunks and, despite its reputation as a vehicle for celebrity gossip, how it might be used in a professional academic context. Following Webster's departure from Anglia Learning \& Teaching (AL\&T), the learning development unit at Anglia Ruskin University (ARU), I took over running the course and updating the content for each iteration due to regular software updates from Twitter.

The ARU version of 10DoT, \#ARU10DoT (Webster and Warnes, 2017), has run once per semester (December and March) since November 2013, attracting around thirty-five participants each time. Content is presented via a WordPress blog (http://aru10dot.wordpress.com) with scheduled posts containing daily tasks. Participants follow the blog using their email address and there is no need to create a WordPress account (although participants may subscribe using an existing WordPress account). Delivered in ten-minute blocks over ten (working) days, \#ARU10DoT supports participants as they create and use their Twitter account.

Access to \#ARU10DoT is not restricted to ARU staff only and anyone can participate. The course thus operates as a mini-MOOC, which was easily manageable prior to the introduction of micro-credentialing (Educause, 2017) in the form of Digital Badges, in March 2017. However, due the amount of time required to monitor participants' progress, this model is not scalable and should the number of participants increase, access to the course will have to be restricted.

\section{Ten Days of Twitter and Beyond}

Course content is delivered via a series of blog posts, each dealing with a single aspect of Twitter. Each day's blog post is edited in advance and scheduled for publication on the appropriate day. The fortnight prior to delivery is spent reviewing the content against Twitter to identify and incorporate any changes that Twitter have made (such as the increase in the number of characters per tweet). Even without any changes, most of the embedded screenshots are replaced, primarily to maintain the currency of the content.

ARU staff are alerted to each delivery via a range of internal communication methods, including the fortnightly staff newsletter, 
announcements on the staff intranet, weekly faculty emails, inclusion on the 'Online learning' section of the AL\&T website (http://arul.ink/ alt-10dot), and, of course, Twitter. In addition, \#ARU10DoT is included in the schedule of CPD events delivered by AL\&T. Although ARU staff are encouraged to register via the HR system, and their participation is checked at the end of the course, calculating exactly how many participants engage with the course is difficult as registration is not compulsory,

That said, on average, not including 'lurkers' who observe but do not actively contribute (Sun, Rau \& Ma, 2014), the course attracts around 30 to 40 participants for each delivery using various access methods: subscription to the blog; bookmarking the blog; or simply following the hashtag or @ handle. At the time of writing, the blog has attracted 2,163 visitors who have viewed the 158 posts 9,195 times.

The WordPress blog posts are disseminated daily via email to those participants who subscribe. Notifications are also publicised via Twitter @ARU10DoT and @MarkWarnes2 (then retweeted by @AngliaLTA); Facebook (my personal account as AL\&T does not currently have a page); Google+ (my personal account as AL\&T does not currently have a page) further iterations will not use Google+ as this was shut down in April 2019; and LinkedIn (my personal account as the AL\&T page does not currently permit this activity). Figure 5.1 shows the ways in which participants access the blog.

\begin{tabular}{lc} 
Subscription Type & n \\
WordPress.com & 24 \\
Email & 111 \\
Social media & 831 \\
Total & 966 \\
\hline
\end{tabular}

Fig. 5.1 Mark Warnes, ARU10DoT blog posts: types of subscription and number of followers (2018), CC BY 4.0

The total for social media combines the numbers of followers for Twitter (@markwarnes2 n=257, @ARU10DoT = 352) and LinkedIn (n=222). These numbers, however, represent potential rather than actual participants. 


\section{Digital Badges}

After running the course in December 2016, the decision was taken to add a micro-credential to the course in the form of a Digital Badge. Digital Badges are available from a range of educational institutions including Lynda.com (2018), Instructure (Canvas LMS), John Wiley and Sons, and the Open University (OU). The OU (2018) offer twenty-six free Badged courses including Digital Literacy: Succeeding in a Digital World.

Digital Badges were first added to \#ARU10DoT in March 2017. This meant a radical redraft of the daily tasks as, to qualify for their Badge, participants needed to record evidence that they had engaged with a task related to that day's post. This shifted the focus of the course from (mainly) passive to (optionally) active, although there remains no compulsion on participants to complete the tasks, other than the desire to qualify for a Digital Badge.

Each daily task covers a specific aspect of Twitter and each task should take no longer than ten minutes to complete. Consequently, if a participant misses a day (or two) it doesn't take long for them to catch up. Ideally participants should complete the course, including the tasks, during the period of delivery, but, acknowledging that some staff may find it challenging to do this, participants are given a further two weeks. Also, all blog posts, for all deliveries, remain available on WordPress, so that participants can work at their own speed.

Those participants who are seeking accreditation must post something either on Twitter or add a comment to that day's blog post:

\section{Week 1}

- Day 1 - Setting up your profile Today's Digital Badge activity is to tell me your Twitter handle using the 'Leave a reply' comment box on this blog post

\section{- Day 2 - Sending tweets}

Today's Digital Badge activity is to tweet 'Joining in \#ARU10DoT with@ARU10DoT and @markwarnes2'

\section{- Day 3 - Following people}

Today's Digital Badge activity is to post, in the comments section 
below, the handles of three interesting people you think others should follow; let us know why you chose them!

- Day 4 - Sending @messages

Today's Digital Badge activity is to send me an @message to tell me how it's going @markwarnes2

- Day 5 - Retweeting

Today's Digital Badge activity is to edit three tweets to add \#ARU10DoT and retweet them

\section{Week 2}

- Day 6 - Hashtags and trending

Today's Digital Badge activity is to post a hashtag of a conversation you'd like to join in the comments section of this blog post

- Day 7 - Pictures and videos

Today's Digital Badge activity is to tweet a picture. Take a picture of your desk, your colleagues, your building, anything you like, and share it with your followers. If you need inspiration then look at the pictures that the people you follow have tweeted. Just make sure you use the \#ARU10DoT hashtag so we can all see it. And, if you're feeling adventurous, there's always video...

- Day 8 - Managing people

Today's Digital Badge activity is to create a list and post the link to this blog page. You might want to try making a list of your colleagues on Twitter, or perhaps one for the professional and funding bodies you follow

\section{- Day 9 - Managing information}

Today's Digital Badge activity is to choose a third party application that looks useful to you, and experiment with it - post below to let us know your thoughts and findings 
- Day 10 - The past and the future

Today's Digital Badge activity is to complete the Satisfaction Survey. OR (if you think that's just too cheeky!) Post a 100-word reflective summary of your experience of the course and whether it has had any impact on your practice

The process of checking that participants had completed the daily tasks proved to be more challenging to manage than originally anticipated, even though this required checking only two possible locations (except for the Satisfaction Survey on Day 10 which is hosted on SurveyMonkey). For one thing, some Twitter posts did not appear in the \#ARU10DoT column in TweetDeck and it was necessary to check participant's tweets. In addition, some participants posted tweets that should have been blog comments, or sent a Direct Message rather than an @message, in which cases the wording of the task was edited for clarity. An additional blog post was published at the end of both the first and second weeks showing participants' progress at those points. Participants were invited to provide evidence in the form of screen shots of any activities I had missed.

As noted above, acknowledging that some participants might be unable to complete the course in the allotted time, they were allowed a further two weeks after the course had finished to complete any outstanding tasks, after which Digital Badges were issued to participants who had completed all ten tasks.

A number of Digital Badge platforms exist (Badge Alliance, 2017), such as Open Badges.me (2016), Mozilla's Open Badges.org (2016), and Credly (2018). Following a review of platforms in 2015, AL\&T had selected Credly as most suited to their needs. The \#ARU10DoT Digital Badges were created and issued using Credly. This involved creating the Badge image along with a course description, complete with a set of criteria confirming the awardee's achievement. Consequently, \#ARU10DoT participants had to create a Credly account to accept and share their badges. Instructions for doing this are provided for participants on the Digital Badges page of the blog and, to date, no-one has raised this as an issue.

Digital Badges can be exported in a number of ways: downloaded in Open Badge format or as a printable PDF, embedded, shared as a link, shared to Open Badges, or shared to social media platforms such 
as Facebook and Twitter, and, possibly most importantly, LinkedIn. Digital Badges exported to LinkedIn appear in the Certifications area of the Achievements section of the profile, and are linked to the issuing institution.

The introduction of Digital Badges had some unintended consequences. For one thing, participants who had completed the course previously, many times in some cases, repeated the course simply to qualify for a Badge. A small number of previous participants asked for a retrospective Badge, hoping to avoid repeating the course, but these requests were denied on the grounds of fairness.

Another unexpected result was the increase in the number of blog hits, which during March 2017 more than doubled the typical traffic. This phenomenon was repeated in December 2017. Although this has not (yet) been systematically researched, it is reasonable to infer that participants were eager to qualify for their Badges.

As the course is open to external participants and its numbers cannot be restricted, it operates like a Mini-MOOC (Massive Open Online Course) (cf. edX, 2016; Coursera, 2018; FutureLearn, undated). However, should the number of external participants increase, it would become impossible to check that all daily tasks had been completed. Should this happen then access to the course would be restricted to ARU staff only.

\section{Impact}

The 10DoT format of daily, bitesize chunks has been adapted by colleagues at ARU for a range of courses including TEL-ve Days of Christmas (Williams and George, 2015), 5 Days of Digital Literacy \#5DoDL (Williams and George, 2016) and its successor, 5 Minutes of Digital Literacy \#5MoDL (Williams and George, 2017, http://arul.ink/ alt-5dodl), both of which offer Digital Badges, and which address ARU's Digital Literacy Framework (Kerrigan \& Evangelinos, 2015), which is in turn based on the EU's DIGCOMP framework for Digital Competence (Ferrari, 2013).

In addition, Dr Toby Carter (Director of Learning, Teaching and Assessment for the Faculty of Science and Technology) has adapted \#ARU10DoT into a module for his MSc Communication Skills for Conservation (Comm4Cons, \#C4C10DoT). The module is delivered via 
the ARU Learning Management System, Canvas, and covers the same content but contextualised for the module (Warnes and Carter, 2016; Carter, 2017).

Twitter analytics also show the impact of @ARU10DoT which tweeted 29 times during December 2017 attracting 5,536 impressions (i.e. '[the number of] Times a user is served a tweet in timeline or search results' (Twitter, 2018) and 564 profile visits. One new follower in December brought 1,355 followers and another in January 2018 brought 2,912 followers, thus increasing the potential reach of the course.

\section{Day Eleven of Ten}

Although the course lasts only ten days, a final Day Eleven post is published on the Monday following the conclusion of the course. An eleventh day had been included in 10DoT from its inception but Carter and East (2017) rewrote the content for \#C4C10DoT. This new content was such a significant improvement on the original text that it was incorporated into \#ARU10DoT.

Topics include tweeting about new publications (with a link to an online version, where possible) and/or relevant new developments in a particular research area or academic subject; publicising events in advance and live-tweeting them on the day; use of hashtags to contribute to conversations; reaching out to new audiences such as government departments, NGOs, businesses, and so on; and monitoring funding sources.

\section{Challenges and Opportunities}

Occasionally, prospective participants have asked for face-to-face delivery, which somewhat defeats the object. That said, an exception was made for a specific purpose when Carter and I were invited to deliver a session on using Twitter for academic purposes for a Faculty CPD Day and we decided to run through \#ARU10DoT in a single twohour workshop slot (Warnes and Carter, 2018). This, however, proved to be a logistical nightmare, mainly due to the range of technological skills of the participants, and it was only possible to complete eight of the ten tasks in the session. Participants were given the opportunity to 
complete the course in their own time to qualify for a Digital Badge. However, only two staff members took the opportunity. That said, according to WordPress statistics, that day recorded the highest number of views of the blog in a single day (43 views from 16 visitors).

\section{Satisfaction Survey}

A link to the SurveyMonkey-hosted Satisfaction Survey (mentioned earlier) is sent via email to all individuals who registered for and/or participated in the course. However, rather than using a simple 'Happy Sheet' (CHRM, 2018) asking participants to rate the course in general, this survey is designed to collect specific data concerning the quality of the content and the impact of the course (Future Work Centre, 2015).

The first two questions invite respondents to explain why, having they registered for the course, they chose not to participate or, having started the course, why they chose not to complete it. Respondents' views on the quality of the daily content is captured using a 'Goldilocks' question (Pappas, 2015), please let me know which topics have too much detail, which have too little, and which are just right. This is followed by questions asking which topics should be abandoned and which are missing. The final question measures the impact of the course by asking if participants have changed the way they use Twitter and, if so, how and why.

Responses from the latest survey show that almost all topics are just right' with the exception of Day 8: Managing People and Day 9: Managing Information, which I shall expand ready for the next delivery. In addition, all participants agreed that the course demonstrated how Twitter can be used in a professional context.

\section{Conclusions and Recommendations}

While a great deal of attention has been paid to developing digital literacy for students (Jisc, 2015), this is an area that also involves staff (HEA, 2017). Only a few short years ago, staff digital literacy included little more than a working knowledge of email, word processing, and PowerPoint. The increasing pervasiveness of social media in everyday life has permeated into the classroom. University staff need 
to engage with the current milieu of information and communication opportunities, in order to both understand their students and to remain relevant in the twenty-first century. Universities must offer CPD that enables staff to expand their skills in this area.

\#ARU10DoT helps academic staff to develop their competence using a social media tool for education and, in doing so, contributes to the requirements of ARU's Digital Literacy Framework. The sustained popularity of the course over five years is testament to its user-friendly mode of delivery, tone and pace, and the addition of Digital Badges has provided additional motivation for participants to fully engage with all aspects of the course.

As 10DoT was created with a Creative Commons license, it has spread throughout the sector and is running at a number of universities, both domestic and overseas, including Regent's University London (\#RUL10DoT), University College Dublin (\#UCD10DoT), University of Liverpool (\#LivUni10DoT), York St John (\#YSJ10DoT), University of Sussex (\#10DOTTEL), Lucerne University of Applied Sciences and Arts (\#HSLU10DoT), and University of Western Ontario (\#MMJC10DoT). Any institution wishing to develop their own version can simply copy, paste and adapt the existing blog posts.

\section{References}

Badge Alliance (2017). 'Badge issuing platforms', http://www.badgealliance. org/badge-issuing-platforms/

Carter, T. (2017). '2017 MOD003368 TRI2 F01CAM: C4C10DoT overview', https://canvas.anglia.ac.uk/courses/2875/pages/c4c10dot-overview

Carter, T. and East, M. (2017). 'Eleventh day of \#C4C10Dot: Beyond C4C10DoT: Twitter and research', https://canvas.anglia.ac.uk/courses/2875/pages/ c4c10dot-day-11

Center for Digital Education (2017). 'Why micro-credentials are taking hold in universities', http://www.centerdigitaled.com/higher-ed/Why-MicroCredentials-Universities.html

Community for Human Resource Management (2018). 'What is a Happy Sheet?', http://www.chrmglobal.com/Qanda/87/1/What-is-a-Happy-Sheet-.html

Coursera Inc. (2018). 'Take the World's Best Courses', https://www.coursera.org/ Credly (2018). 'What's your Digital Credential Strategy?', https://credly.com/ 
EDUCAUSE Learning Initiative (2017). '7 things you should read about microcredentialing/digital badging', https://library.educause.edu/ /media/ files/library/2017/7/elir1704.pdf

edX (2016). ‘Mooc.org', http://mooc.org/

Ferrari, A. (2013). DIGCOMP: A Framework for Developing and Understanding Digital Competence in Europe. Luxembourg: Publications Office of the European Union, http://ftp.jrc.es/EURdoc/JRC83167.pdf

FutureLearn (n.d.). Learn new skills, pursue your interests, advance your career, https://www.futurelearn.com/

Future Work Centre (2015). 'Beyond the happy sheet: Adopting an evidence-based approach to training and development evaluation', http://www.futureworkcentre.com/wp-content/uploads/2015/09/FWC_ BeyondHappySheet.pdf

Higher Education Authority (HEA) (2011). 'The UK professional standards framework for teaching and supporting learning in higher education', https://www.heacademy.ac.uk/system/files/downloads/uk_professional_ standards_framework.pdf

Higher Education Authority (HEA) (2017). 'Digital literacies', https://www. heacademy.ac.uk/knowledge-hub/digital-literacies

Jisc (2015). 'Developing students' digital literacy', https://www.jisc.ac.uk/ guides/developing-students-digital-literacy

Kerrigan, M. and Evangelinos, G. (2015). 'Digital literacy framework (V.6)', Anglia Ruskin University, https://vle.anglia.ac.uk/sites/LTA/Course\%20 Documents/Digital_Literacy/Digital\%20Literacy\%20Definitions\%20v6.pdf

Lynda.com (2018). 'Lynda.com certificates of completion - frequently asked questions', https://www.linkedin.com/help/lynda/topics/10083/10084/70176

Openbadges.me (2016). 'Design and issue Open Badges', https://www. openbadges.me/

OpenBadges.org (2016). 'Discover Open Badges', https://openbadges.org/

Open University (2018). 'Badged courses', http://www.open.edu/openlearn/getstarted/badges-come-openlearn

Pappas, C. (2015). '6 tips to apply the goldilocks principle in eLearning', https:// elearningindustry.com/6-elearning-tips-to-apply-the-goldilocks-principlein-elearning

Parr, C. (2017). 'The top 10 UK Higher Education social media superstars of 2017', Times Higher Education, https://www.timeshighereducation.com/blog/ top-10-uk-higher-education-social-media-superstars-2017

Prensky, M. (2001). 'Digital natives, digital immigrants part 1', On the Horizon, 9:5, pp. 1-6, https://doi.org/10.1108/10748120110424816 
Sun, N., Rau, P. P. and Ma, L. (2014). 'Understanding lurkers in online communities: A literature review, Computers', Human Behavior, 38, September 2014, pp. 110-17, https://doi.org/10.1016/j.chb.2014.05.022

Twitter (2018). 'About your activity dashboard', https://help.twitter.com/en/ managing-your-account/using-the-tweet-activity-dashboard

Warnes, M. and Carter, T. (2016). 'Ten days of Twitter and beyond', paper presented at 17th Annual Learning and Teaching Conference, Anglia Ruskin University, 23 June 2016, http://www.lta.anglia.ac.uk/annual.php/SessionAbstracts-and-Presentations-49/

Warnes, M. and Carter, T. (2018). 'Develop Your Use of Twitter', workshop delivered at ALSS CPD Day, 5 January 2018.

Webster, H. (2013). ‘\#10DoT ten days of Twitter', https://10daysoftwitter. wordpress.com/

Webster, H. and Warnes, M. (2017). '\#ARU10DoT ten days of Twitter', https:// aru10dot.wordpress.com/

Williams, J. and George, J. (2015). 'TEL-ve days of Christmas', https://telvedays ataru.wordpress.com

Williams, J. and George, J. (2016). '5 days of digital literacy', https://5daysof digitalliteracy.com/

Williams, J. and George, J. (2017). '5 minutes of digital literacy', https://canvas. anglia.ac.uk/courses/2224

Williams, J. and Warnes, M. (2018). ‘\#SocMedHE17', https://www.anglia.ac.uk/ blogs/socmedhe17 